\title{
Thermal Management of High-Power Density Electric Motors for Electrification of Aviation and Beyond
}

\author{
David C. Deisenroth and Michael Ohadi *
}

Department of Mechanical Engineering, University of Maryland, 8228 Paint Branch Dr., Rm 3131, College Park, MD 20740, USA; ddeisenr@umd.edu

* Correspondence: ohadi@umd.edu; Tel.: +301-405-5263

Received: 16 April 2019; Accepted: 24 August 2019; Published: 20 September 2019

\begin{abstract}
Enhanced cooling, coupled with novel designs and packaging of semiconductors, has revolutionized communications, computing, lighting, and electric power conversion. It is time for a similar revolution that will unleash the potential of electrified propulsion technologies to drive improvements in fuel-to-propulsion efficiency, emission reduction, and increased power and torque densities for aviation and beyond. High efficiency and high specific power $(\mathrm{kW} / \mathrm{kg})$ electric motors are a key enabler for future electrification of aviation. To improve cooling of emerging synchronous machines, and to realize performance and cost metrics of next-generation electric motors, electromagnetic and thermomechanical co-design can be enabled by innovative design topologies, materials, and manufacturing techniques. This paper focuses on the most recent progress in thermal management of electric motors with particular focus on electric motors of significance to aviation propulsion.
\end{abstract}

Keywords: electric aircraft; motor cooling; thermal management

\section{Introduction}

The global fleet of aircraft is projected to more than double to 48,000 in the next 20 years. The increase in air travel is driven by population, economic growth, and the growing global middle class [1]. One of the largest single expenditures of airlines is jet fuel, accounting for around $20 \%$ of annual expenditures [2]. Electric motor propulsion may reduce this cost by improving aerodynamic efficiency through wider implementation of distributed propulsion, beyond the typical maximum of four propulsors per plane in production jet-engine aircraft, as shown in Figure 1 [3-6]. Other benefits of electric motor propulsion include reduced noise and vibration.
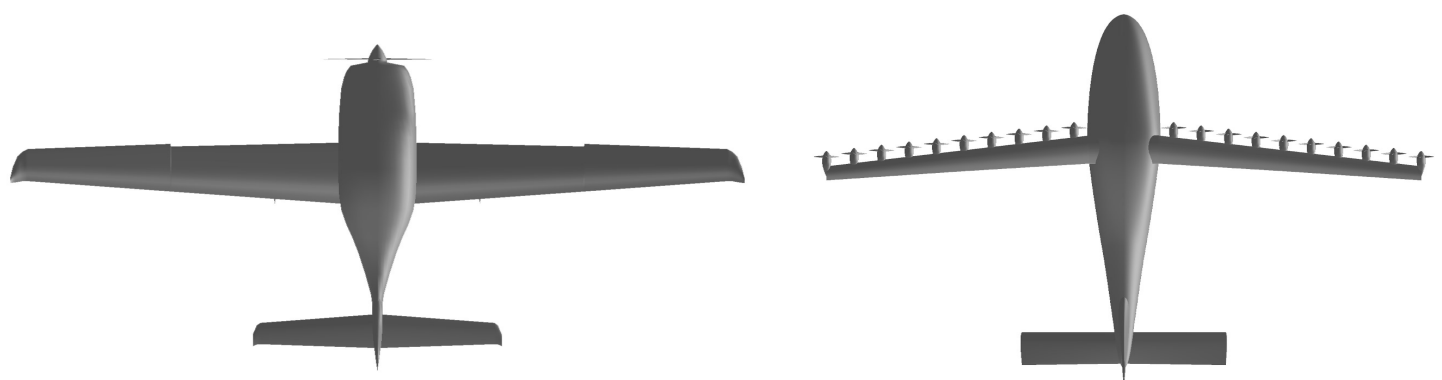

Figure 1. Example of distributed propulsion aircraft architecture.

For widespread electric propulsion to be feasible, the motors must be highly power-dense. High gravimetric power density increases aircraft efficiency by decreasing the takeoff weight, while increased volumetric power density decreases frontal area and drag [7]. Currently, though, commercial 
high-power density motors can continuously operate at only about $5 \mathrm{~kW} / \mathrm{kg}$. The thermal limitation of the motor is demonstrated by peak power output of more than $10 \mathrm{~kW} / \mathrm{kg}$, but the duration is limited to about $20 \mathrm{~s}$ before the temperature rise becomes unmanageable [8-10]. High conversion efficiency is also desirable, because, for example, a motor producing $60 \mathrm{~kW}$ of rotor power and operating at $95 \%$ efficiency produces $3 \mathrm{~kW}$ of heat. In aircraft, heat generation is onboard energy (storage mass) that is not used for propulsion, but higher capacity cooling systems are generally larger and heavier. Therefore, to increase the feasibility of electric aircraft via the integration of high-performance cooling systems, continuous motor power density must be increased while maintaining efficiency. Developments in high-power density motors may also increase the feasibility of electric personal transporters, multi-passenger vehicles, and trains, as well as compact electricity generators.

\subsection{Electric Propulsion Motor Architectures}

The intrinsic compactness of permanent magnet motors-generated without bulky electromagnets within the rotor-coupled with more efficient operation make this motor architecture advantageous for aircraft propulsion. Most permanent magnet motors have an electromagnetic stator that synchronously drives the permanent magnet rotor, which then transmits the power to the propulsion blades. Figure $2 \mathrm{a}$ shows a constructed radial flux permanent magnet motor that could drive an aircraft propeller. Figure $2 \mathrm{~b}$ shows a computer aided design (CAD) radial cross-section of a similar, simplified, motor for illustration of the primary heat generation sites in such a motor.

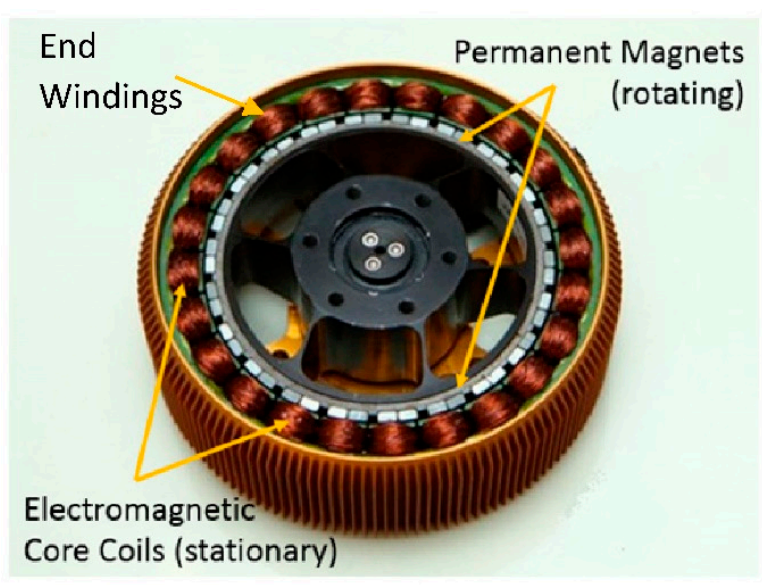

(a)

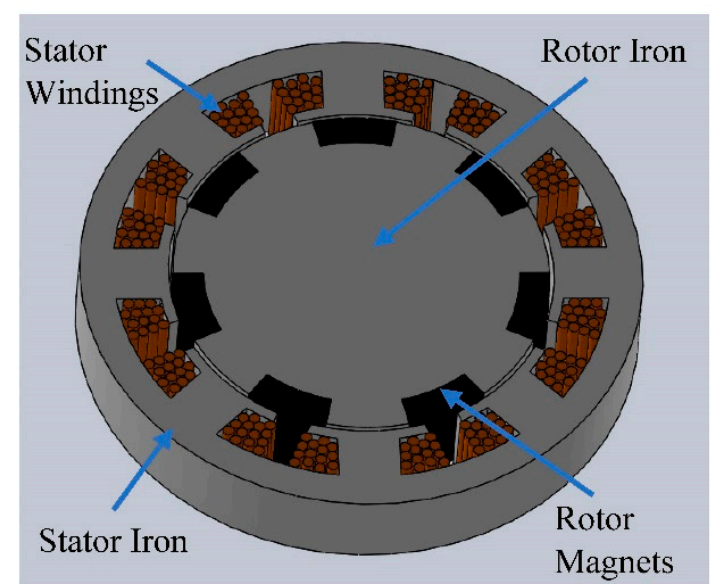

(b)

Figure 2. Radial flux permanent magnet electric motors: (a) digital image, and (b) computer aided design section view [9].

Figure 3a shows an exploded view of an axial flux permanent magnet motor, while Figure $3 \mathrm{~b}$ shows an axial cross section of the same motor. Axial flux motor architectures produce magnetic flux along the motor axis, necessitating that the rotor and stator be the same diameter and adjacent along the axis of the motor. Axial flux motors driving a single font propeller have been demonstrated in high performance electric aircraft racing [11].

As shown in Figure 4, four common types of motor architectures have been demonstrated for electric propulsion. Figure 4a is perhaps the most "traditional" motor architecture, in which the stator circumferentially surrounds the rotor, which drives a shaft. The magnetic flux occurs radially from the stator windings to the permanent magnets. Figure $4 \mathrm{~b}$ shows a somewhat similar configuration to Figure 4a, except the rotor is hollow, allowing propulsion blades to be contained inside the rotor. This is said to be an "inrunner" rotor design. Figure 4c illustrates an "outrunner" rotor design, in which the stator is contained within the rotor, which may have blades on its exterior. "Double runner" rotors combine the inrunner and outrunner configurations, and may result in increased efficiency 
at the cost of increased manufacturing complexity [12]. Figure $4 \mathrm{~d}$ shows a similar cross-section of an axial flux permanent magnet motor, which most often is available in a shaft-drive configuration. Propulsion configurations include fixed pitch propellers, variable pitch propellers, contra-rotating (counter-rotating) fans or propellers, ducted fans, and rim driven fans [13]. Each of these configurations may be compatible with distributed propulsion.

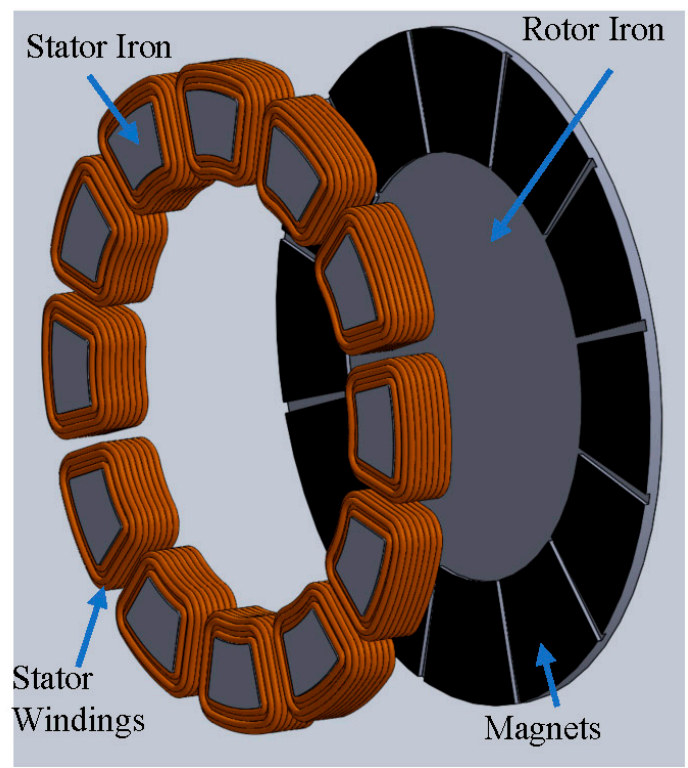

(a)

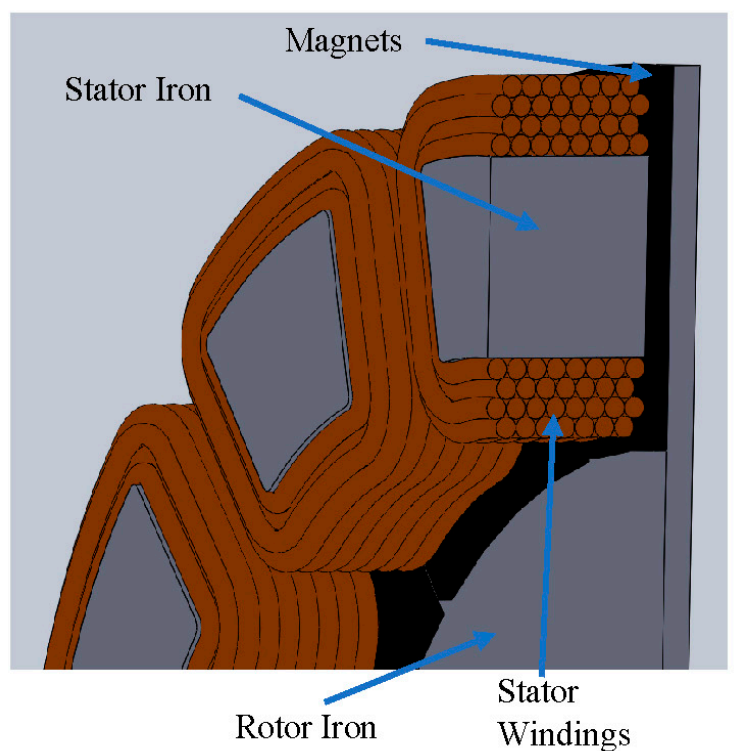

(b)

Figure 3. CAD illustration of an axial flux permanent magnet electric motor: (a) exploded view of rotor and stator, and (b) axial cross-section of the axial flux permanent magnet motor.

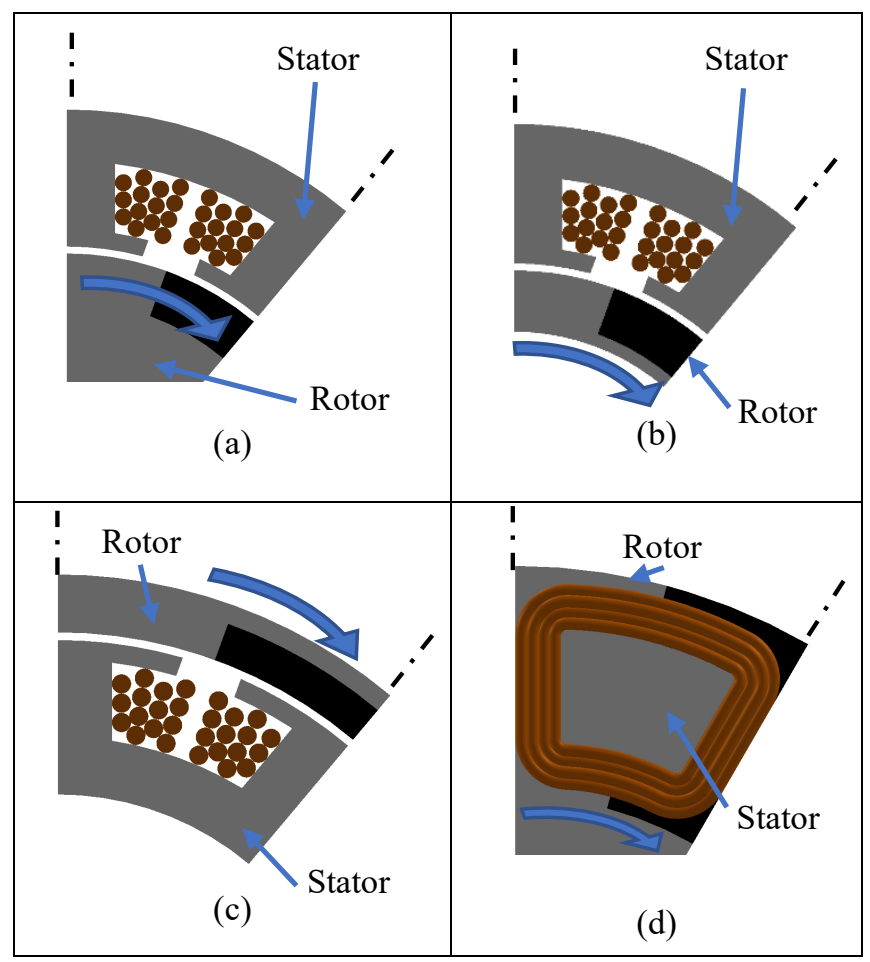

Figure 4. Electric propulsion motor architectures: (a) Radial flux shaft drive; (b) radial flux inrunner rim drive; (c) radial flux outrunner drive; (d) axial flux shaft drive. 


\subsection{Heat Generation and Loss Mitigation}

Like any electrical device, permanent magnet motors generate heat. For example, a motor producing $60 \mathrm{~kW}$ of rotor power and operating at $95 \%$ efficiency produces $3 \mathrm{~kW}$ of heat. Without adequate cooling, heat generation causes temperature rise, which has many detrimental effects. First, excess temperature may cause catastrophic failure by the loss of integrity of the polymer electrical insulation and bonding materials. Second, temperature cycles cause mechanical stresses due to thermal expansion, resulting in fatigue, which is exacerbated by the magnitude of the thermal cycles. In electric motors, the coefficient of thermal expansion of the permanent magnet materials is about double that of silicon steel, which can result in mechanical failure of magnets with excess temperature cycling [14]. Loss of permanent-magnet functionality may also occur via demagnetization at high temperatures [14].

Temperature rise is also associated with decreased efficiency of electric motors. The electrical resistivity of copper increases with temperature, increasing the thermal load generated by Joule heating as temperature rises. Reduced efficiency may also occur due to decreased permanent magnet performance (reduced remanence and coercivity) at elevated temperatures [14].

A heat generation (loss) mitigation strategy that has long been integrated into motors is use of laminated rotor and stator iron. The electrical insulation between the high magnetic permeance silicon steel sheets increases the electrical flow path resistivity within the material, and therefore decreases eddy currents and iron losses. The same strategy may be applied to permanent magnets to reduce magnet losses [14]. It should be noted, though, that electrical insulation is often also thermal insulation, which reduces cooling performance for the remaining heat load. The bonding material that holds permanent magnets in place is also a thermal resistance, but in most cases, heat generation in the permanent magnets is less than either the copper or iron [14].

In modern motors, the largest contributor to heat generation is the copper stator windings. For example, in the optimized air-cooled motors for the NASA SCEPTOR program, the copper (resistive) losses contributed $43 \%$ of the total thermal load, while the iron losses (primarily due to Joule heating by eddy currents) contributed $37 \%$, and the permanent-magnet rotor load contributed the balance of $20 \%$ [12]. Depending on the motor configuration and operating conditions, copper losses may be the dominant source of heat generation, with values upward of $64 \%$ of the total [15].

The primary approach to maximizing efficiency is to model and optimize the motor parameters. The NASA SCEPTOR motors were modeled with a two-dimensional finite element analysis [12]. The variables in the optimization include rotor configuration (inrunner, outrunner, or double runner), number of stator slots and rotor poles, ratio of number stator slots to rotor poles, motor mass, operating speed, torque, voltage, lamination dimensions, magnet type, stator fill factor, yoke material, stack length, rotor and stator inner and outer diameters, magnet thickness, airgap distance, slot height, tooth width, and tooth tip width [12]. The importance of optimization for aircraft electric propulsion was well illustrated by the Pareto fronts, which clearly indicate that there is a tradeoff between motor mass and efficiency, as shown in Figure 5.

After optimization, the selected design was an outrunner with a stationary interior housing, which contained the stator and cooling fins. The outrunner was chosen for the best tradeoff between mass, efficiency, and manufacturability. The propulsion blades were mounted on the exterior of the outrunner, which was contained within a nacelle. In the outrunner design, centrifugal force aids in retention of the permanent magnets within the rotor, requiring only weak bonding material, which may improve reliability and reduce thermal resistance to magnet heat dissipation. It was found that the air-cooling system contributed $1.6 \%$ to cruise drag. Furthermore, the limitations of air cooling are highlighted by the $60 \mathrm{~kW}$ motor with a power density of only $2.7 \mathrm{~kW} / \mathrm{kg}$ [12]. The next sections will describe liquid cooling techniques that increase the levels of heat dissipation beyond those practical with air cooling. 

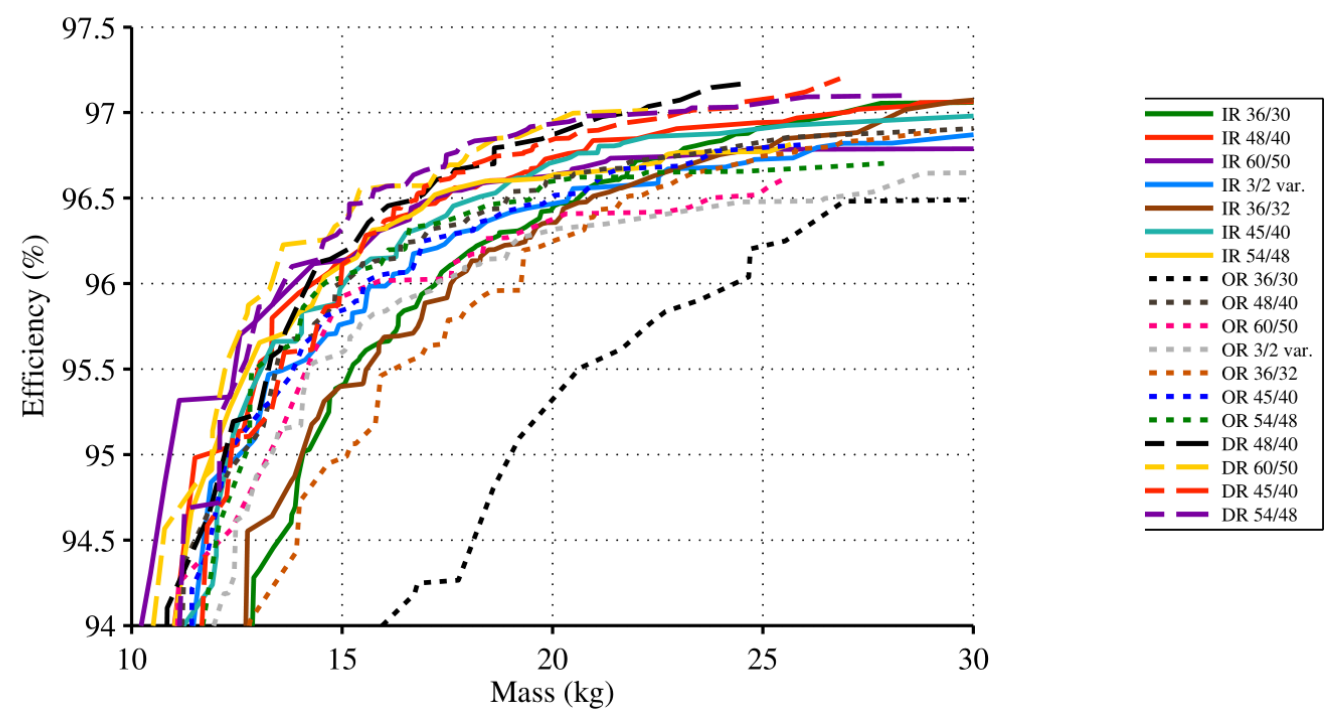

Figure 5. Edges of Pareto optimal fronts for design of the NASA SCEPTOR electric propulsion system. In the legend, IR indicates inrunner, OR indicates outrunner, and DR indicates double runner. The ratios in the legend are the number of stator slots to the number of rotor poles (stator slots/rotor poles).

\subsection{Heat Rejection}

The focus of this review is on the approaches that have been developed to extract heat from high-power density motors. A problem that remains, though, is heat rejection from the plane to the environment, which is not trivial. Current aircraft reject heat for a variety of purposes through a variety of mechanisms.

Fuel-oil heat exchangers are commonplace on commercial aircraft. Oil cooling is essential for engine oil to retain appropriate viscosity for lubrication, and fuel is an excellent coolant. Therefore, fuel cooling may be useful for hybrid aircraft, although it must be assured that proper fuel flow is maintained for motor cooling even when the turbofans and electric motors are not used simultaneously [16]. Another approach to oil cooling is an air-oil heat exchanger. These heat exchangers have been demonstrated in the EM-11 ORKA aircraft, in which multiple kilowatts of heat are dissipated from the oil-air heat exchanger [17]. For electric aircraft using ducted fans, a similar bleed air scheme could also potentially be used to reject heat from the motor coolant.

Until the roll-out of the Boeing 787, most commercial jetliners used engine compressor bleed air for cabin cooling [18]. The 787 uses a dedicated electric compressor for the air cycle machine environmental control system. A similar concept may be used to reject heat from the motor coolant in electric aircraft. Regardless of the approach, heat rejection from the electric motors is an essential area of research to bolster the technologies that enable more-electric aircraft. The next sections of this review will focus on heat extraction from motors and other power dense electric devices.

\section{Established Cooling Approaches}

\subsection{Oil Bath Cooling}

Oil bath cooling increases the heat dissipation ability of the cooling system beyond air cooling. With this configuration, oil is contained within the motor housing and is exposed to the stator windings, stator iron, and rotor. Having the stator and rotor partially or fully submerged in oil causes two problems: the electromagnetic efficiency may be decreased by the fluid in the airgap, and viscous losses occur because of the stirring of the oil by the rotor. Due to these conditions, the fluid must also be chemically stable and non-flammable, and have high magnetic permeability and high electrical resistivity [19]. Automatic transmission fluid (ATF) is often chosen for this application. The ATF may either be passively or actively pumped to an external heat exchanger. 
In the case of a production traction motor, the motor was partially filled with oil. In this arrangement, oil may be entrained with the rotor and sprayed about within the enclosure, generating an effect similar to jet impingement or non-evaporative spray cooling [19]. Alternatively, the motor enclosure may be entirely submerged [15]. Although oil bath cooling is an improvement from air cooling, commercial motors with power densities of $5 \mathrm{~kW} / \mathrm{kg}$ require water jacket cooling.

\subsection{Water Jacket Cooling}

The highest performance commercial motors can power racing aircraft, sustain more than $5 \mathrm{~kW} / \mathrm{kg}$ power density, and sprint for power densities up to $12.1 \mathrm{~kW} / \mathrm{kg}$ [10]. The peak power of the $14 \mathrm{~kg}$ motor was $170 \mathrm{~kW}$, and the peak torque density was $17.9 \mathrm{~N}-\mathrm{m} / \mathrm{kg}$. These axial flux permanent magnet motors are cooled by a water jacket. Axial flux architectures are particularly compatible with circumferential water jacket cooling because a large area of the high thermal conductivity copper windings can be put in contact with the water jacket. This contrasts with radial flux motors, which have a low thermal conductivity steel stator body between most of the winding area and the water jacket. Water jacket cooling may be achieved by circumferential flow paths, helical ducts, axial serpentine channels, or circumferential serpentine channels. Although water jacket cooling is a robust design that has achieved quite high performance, there remains room for improvement in motor cooling, which will next be discussed.

\subsection{Heat Pipe Cooling}

Modern portable devices increasingly use "heat pipes." The flow in heat pipes is typically driven by a capillary wick, which transports liquid from the condenser back to the evaporator. A burgeoning area of study is "pulsating heat pipes," which are not limited by relatively weak capillary forces driving standard heat pipes, while still utilizing passive (pumped by internal fluid forces) phase change cooling. In pulsating heat pipes, the flow is driven by differential bubble expansion and contraction in the evaporator and condenser sections [20]. Water is often the working fluid for these two types of heat pipes. A recent study used micropillar wicks for passive, capillary-pumped evaporation of water, achieving a peak semiconductor chip-scale heat flux of $45 \mathrm{~W} / \mathrm{cm}^{2}$ at $19{ }^{\circ} \mathrm{C}$ superheat before becoming limited by the efficacy of capillary pumping [21]. These passive systems may produce HTC's comparable to pool boiling, on the order of $10,000 \mathrm{~W} / \mathrm{m}^{2} \mathrm{~K}$, which are suitable for many modern applications.

The concept of heat pipe cooling has been applied to electric motors for many decades [22]. It has been shown that heat pipes integrated into the external fins of a motor can decrease the external temperature of the motor from $102{ }^{\circ} \mathrm{C}$ to $68^{\circ} \mathrm{C}$, reducing the thermal resistance from $0.5^{\circ} \mathrm{C} / \mathrm{W}$ to $0.28^{\circ} \mathrm{C} / \mathrm{W}$ with a heat load of $150 \mathrm{~W}$. Studies and patents have been developed for integrating capillary heat pipes into stator windings [23]. Higher power-output and power-density motors require rotor cooling as well [24]. As a result, rotating capillary [25,26] and rotating pulsating heat pipes [27] have been developed and applied to electric motor cooling. There is even interest in implementation of heat pipes in traction motors of modern automobiles [28].

However, as motors become more power dense, the need for higher cooling density than can be provided by heat pipes is increasing. Pumped two-phase cooling is advantageous because two-phase pumped cooling can remove more heat per pumping power than single-phase pumped cooling when configured correctly, although much research remains to be done in predictive modeling of heat transfer and pressure drop in diabatic two-phase flows [29-31]. The primary focus of the research to be presented in the remainder of this publication is on pumped single-phase cooling systems, which-with some modification-may also be compatible with high heat flux pumped two-phase cooling.

\section{Experimental Thermal Improvements}

The following discussion will describe experimental heat transfer improvements that have been applied in research environments to push the envelope of electric motor performance. As discussed 
previously, the majority of heat production occurs in the copper windings of the stator, and the second-largest heat production source is iron losses in the stator and rotor. The following sections will describe improvements to the thermal performance of the stator iron, as well as varying approaches to winding cooling, including inter-winding cooling (between windings) and intra-winding cooling (within windings).

\subsection{Stator Iron Thermal Enhancement}

Pyrhonen et al. [32] demonstrated an intra-iron cooling improvement in an axial flux motor, dual stator, single rotor configuration. In this study, copper rods were embedded in stator iron to significantly improve the heat conductivity from the stator iron losses to the cooling water heat exchanger on the opposite side of stators from the rotor, as illustrated in Figure 6. This thermal enhancement is significant, because the high thermal conductivity copper paths are perpendicular to the thermal resistances generated by electrical insulation between the stator iron laminates. The copper heat conductors created a continuous thermal path from the interior of the stator iron into the cooling water, where they protruded into the flow. In addition to the copper heat conductors, aluminum oxide based Ceramacast $675-\mathrm{N}$ potting material with thermal conductivity of $100 \mathrm{~W} / \mathrm{m}-\mathrm{K}$ was added between the stator end windings and water jacket, further improving the thermal performance of the stator.

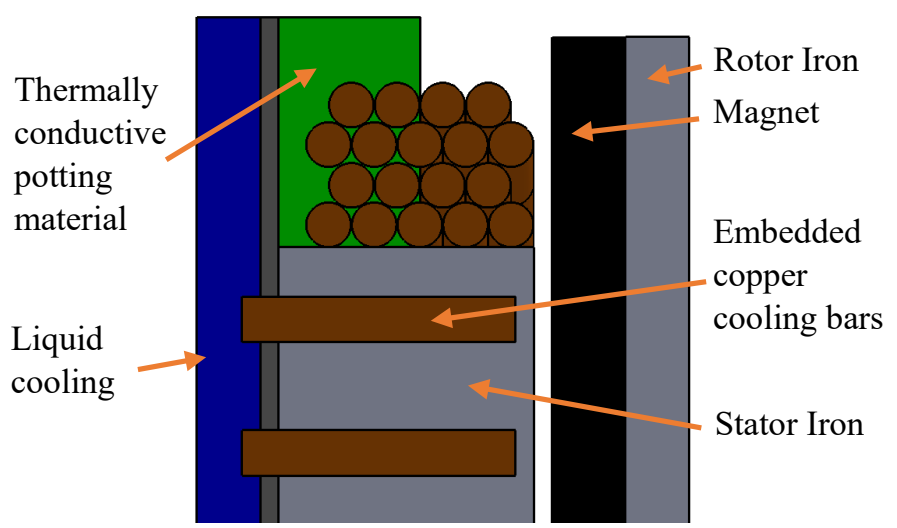

Figure 6. Illustration of intra-iron copper cooling paths and thermally conductive end winding potting material in an axial flux, permanent magnet motor.

The study by Pyrhonen et al. [32] independently showed the degree to which one copper bar per stator tooth, three conductive bars per stator tooth, and the potting material on the end windings improved the thermal performance. A single copper bar in each stator tooth decreased the winding temperatures by about $15^{\circ} \mathrm{C}$, while three copper bars further decreased the winding temperatures by about $10^{\circ} \mathrm{C}$. Under the same conditions, the potting material had an effect of cooling the windings by less than $2{ }^{\circ} \mathrm{C}$. Ultimately, the improved motor could operate continuously at $75 \mathrm{~kW}$ power output, while in stock configuration it exceeded the temperature limit of $130^{\circ} \mathrm{C}$ after $70 \mathrm{~min}$ of operation at the same power output.

Pyrhonen et al. [32] further showed an important codesign consideration for intra-iron improvements. It was found that a detriment of a 3\% increase in stator iron losses was caused by decreased iron area that was occupied by the copper bars. Therefore, the addition of copper bars caused a decrease in electromagnetic performance of the stator for an improvement in the overall performance of the motor. This example illustrates the sometimes-conflicting performance interaction of thermal and electromagnetic systems; and provides further evidence of the importance of accurate; combined thermal and electromagnetic modeling of further development of high-performance motors. 


\subsection{Inter-Winding Cooling}

A simple but effective approach to inter-winding cooling was demonstrated by Rhebergen et al. [33]. The approach brings heat exchange channels into direct contact with the stator windings by placing the channels in the interior of the winding in the gap between stator teeth at the air gap. This position is illustrated in Figure 7, with the IW position. In the design, the channels ran in a serpentine path, cooling several windings in one fluid pass. The cooling channels were modeled as a thermally conductive polymer in order to have a relative permeability near unity. Contact resistance was eliminated by bonding the cooling channels to the windings with the thermally enhanced polymer with thermal conductivity of $2 \mathrm{~W} / \mathrm{m}-\mathrm{K}$. Simulations predicted that with water supplied at room temperature, the peak temperatures of the stator and windings could be reduced by nearly $100^{\circ} \mathrm{C}$ with a $5 \mathrm{~kW}$ heat load, when compared to the standard natural convection case, to approximately $133^{\circ} \mathrm{C}$. The inter-winding cooled motor, therefore, could operate at much higher power than it could with its original configuration while maintaining the integrity of its electrical insulators.

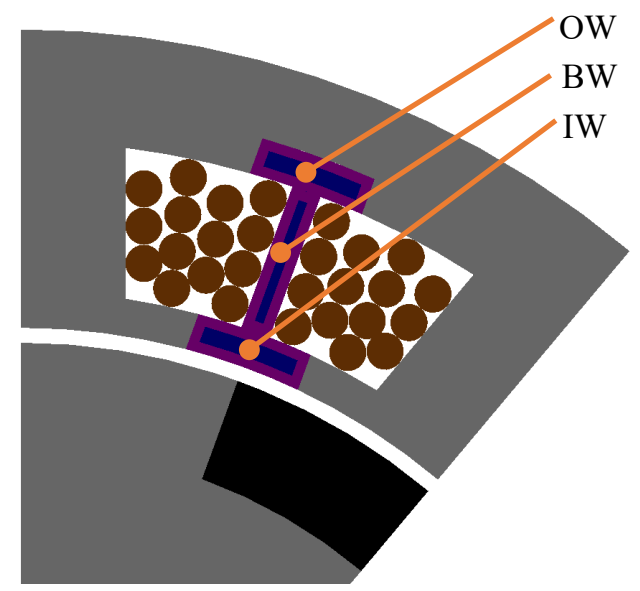

Figure 7. Illustration of three heat exchanger positions in radial flux motor inter-winding positions demonstrated in the literature: outside of windings (OW), between windings (BW), and interior of windings (IW).

Sixel et al. [34] additively manufactured a polymer heat exchanger that facilitated flow channels between the coil windings (BW in Figure 7) and on the outside of the coil windings (OW in Figure 7). The flow channels were designed to be aluminum filled polycarbonate with thermal conductivity of $1 \mathrm{~W} / \mathrm{m}-\mathrm{K}$ by fused deposition modeling [34]. The water-cooling channels occupied the OW and BW positions shown in Figure 7. It was concluded that that a $44 \%$ decrease in the winding temperature rise can be achieved by this inter-winding heat exchanger when it is used as an enhancement from the standard water jacket cooling.

Semidey and Mayor [35] designed, fabricated, and tested an internally micro-featured heat exchanger that was placed between the windings (BW position in Figure 7). The heat exchanger was fabricated by machining microfeatures into copper plates. Two halves were then assembled to form a channel for water flow. It was found that the base motor (Golden Motor HPM-10KW) could handle a steady-state current density of $8.24 \mathrm{~A} / \mathrm{mm}^{2}$ and a transient current density of $14.7 \mathrm{~A} / \mathrm{mm}^{2}$. After installation of the inter-winding heat exchanger between the stator windings, the machine was capable of a steady current density in excess of $24.7 \mathrm{~A} / \mathrm{mm}^{2}$ and transient current density of more than $40 \mathrm{~A} / \mathrm{mm}^{2}$ with class $\mathrm{F}$ insulation, which is limited to an operating temperature of $155^{\circ} \mathrm{C}$. Although it could not be confirmed due to test bench limitations, it may be estimated that the improved motor produced approximately three times more power than in the stock configuration. 


\subsection{Intra-Winding Cooling}

Lindh et al. [36] demonstrated an intra-winding cooling method for an axial flux permanent magnet synchronous machine, as illustrated in Figure 8. Stainless steel coolant conduits were tightly wrapped with stranded Litz wire, and the coaxial tubing and electrical conductor served as the stator windings. A shortcoming of the long coaxial fluid flow path occurred with polyalphaolefin oil as the cooling fluid, in which the pressure drop was nearly 6 bar. Nevertheless, it was found that compared to the stock motor, intra-winding oil cooling decreased the average end winding temperature by $67^{\circ} \mathrm{C}$, while intra-winding water cooling decreased the average end winding temperature by $97^{\circ} \mathrm{C}$. The stock winding current density reached $4 \mathrm{~A} / \mathrm{mm}^{2}$, while the thermally improved motor produced $14 \mathrm{~A} / \mathrm{mm}^{2}$, an improvement that corresponds to more than a factor of three in motor power and torque density.
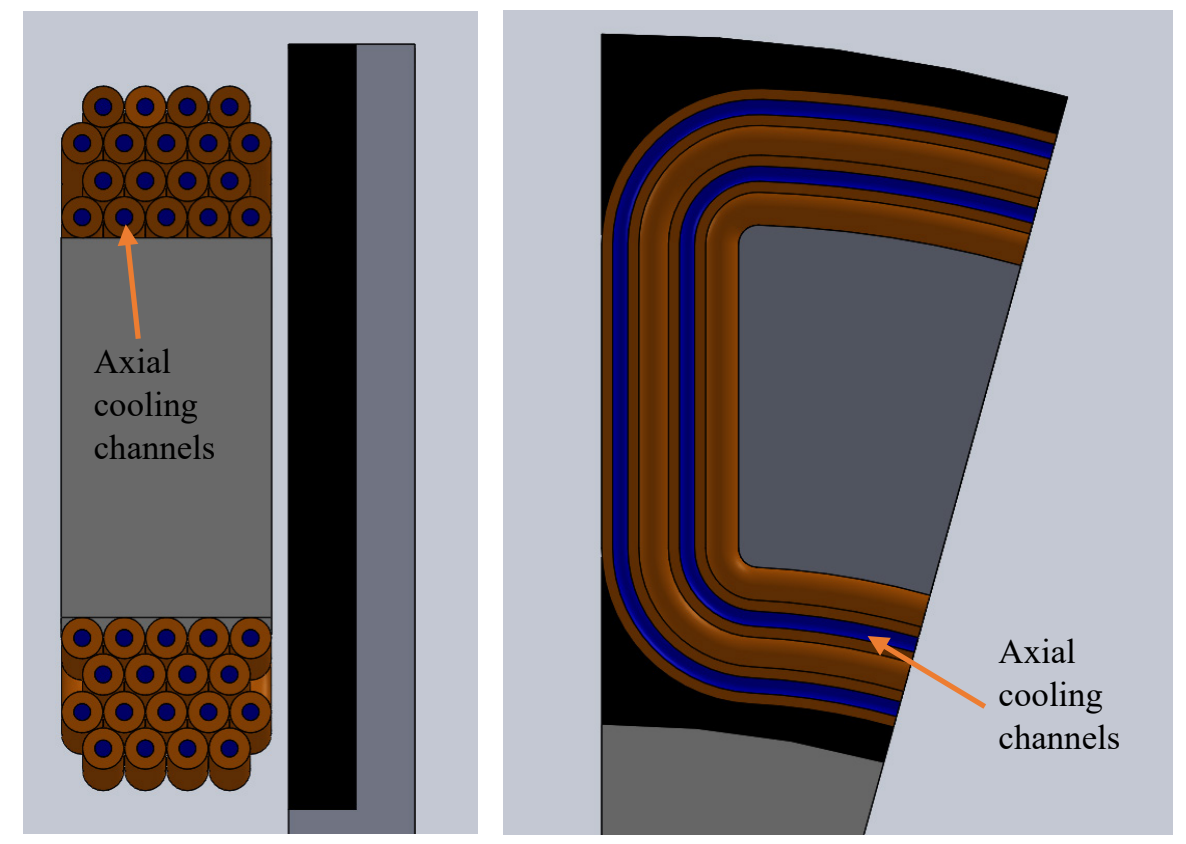

Figure 8. Illustration of intra-winding coaxial cooling paths within stator windings of an axial flux, permanent magnet motor.

Wohlers et al. [37] demonstrated a different approach to intra-winding cooling than Lindh et al. [36] via additive manufacturing of the coil windings with integrated cooling channels. In the design, a single coil occupied about half the width of stator slot, with 11 wraps around each stator tooth. Typically, this large electrical cross section in the winding would cause large current density disparities, or current crowding, leading to reduced efficiency. The geometrical freedom of additive manufacturing, though, allowed Wohlers et al. [37] to locally tune the winding cross section to significantly increase the current density uniformity. Furthermore, the cooling channels were not constrained to a coaxial configuration but were instead routed to have inlets and outlets on either end of the stator, which could significantly reduce the pressure drop per cooling capacity of the system. The windings were laser sintered from AlSi10Mg powder, an alloy that has approximately double the electrical resistance, and therefore, heat generation per current density as copper. It was found that the steady-state current density of the coil geometry could reach $58.5 \mathrm{~A} / \mathrm{mm}^{2}$. Extrapolating from those results, it was determined that with a similar configuration, cast copper could possibly reach current density of $130 \mathrm{~A} / \mathrm{mm}^{2}$, which is about five times the current state of the art in electric motors.

\section{Integrated Motor Drives}

Motor drives are essential for realizing the benefit of permanent magnet synchronous motors. The motor drive takes power from a source and can use feedback control to convert that power into 
transient control of the magnetic field produced by the stator windings. Automotive companies have already integrated motor drives (IMD) with transaxle assemblies, eliminating large power and communication cables running between the motor and controller, as well as eliminating the separate enclosure required for the power and logic components of the motor drive. In the production hybrid-electric automobile, the motors were cooled by ATF, while the power electronics were water cooled [38].

The same advantages that make IMD's essential in automotive applications also make IMD's essential in electric aircraft. In continued development of IMD technology, it is projected that in the near future, motor drives may be completely embedded in the motor enclosures, generating a negligible effect on the motor mass and volume [38]. The advantages of IMD's may be further realized by wireless signal control, which would eliminate motor control signal cabling weight and space requirements in aircraft, which is particularly important for distributed propulsion designs with many motors.

Perhaps the most important technological innovation that enables integrated motor drives is wide bandgap electronics, such as $\mathrm{SiC}$ and $\mathrm{GaN}$, because of their comparatively high-power density over more traditional Si devices. The benefits of wide bandgap devices also include higher switching speed and higher temperature operation [38]. Although higher temperature operation somewhat eases the need for highly effective thermal management, the factor of five increase in power density of motor drives enabled by wide SiC devices often necessitates the need for liquid cooling while Si devices may more readily be air cooled [38].

In addition to decreasing the size and weight required by the drive electronics, wide bandgap electronics $(\mathrm{GaN})$ can be used to develop motors with different manufacturing approaches from commonly used methods. As reported by Jahns et al. [38], Wang [39] developed motor drive modules that were integrated into segmented sections of the stator, bringing the vision of fully integrated drive electronics closer to reality. From the increasing importance of IMD's in electric motors, and their clear advantages for aerospace applications, the challenge of thermal management of motors becomes coupled with that of high heat flux power and logic electronics. Jahn et al. [38] concluded that in order for the vision of fully integrated, highly compact motor drives to become realizable, multi-disciplinary, multi-physics approaches are needed.

\section{Lessons from High-Performance Electronics}

As power electronics increasingly need pumped fluid cooling and drive electronics are increasingly integrated into motors, the symbiosis between high heat flux electronics and high-power density motors is increasing. Further, with wide bandgap semiconductors, the need for pumped single- and two-phase cooling for logic and power devices is increasing [40,41]. As well, at the same time, logic and power devices are increasingly integrated with electric machines [38]. So, although the thermal management challenges of motors and semiconductors are intercoupled, industry and research in thermal developments in motors lags that of semiconductors.

The motivation for thermal management in semiconductors is comparable with that of motors. At temperatures approach their upper operation limit, semiconductor devices typically exhibit decreased functionality and efficiency, producing less desirable power output per input, and then total loss of functionality $[42,43]$. Mechanical fatigue considerations in semiconductor packages are similar to that for motors, in which thermal cycling fatigue occurs due to bonded ceramic, metallic, and polymer materials with vastly differing coefficients of thermal expansion [42].

Historically, the cooling capability and performance of semiconductor thermal management systems has increased [44]. Early semiconductor devices utilized crude cooling systems, primarily relying on spreading across a somewhat increased surface area to dissipate to the ambient. As devices have innovated, so have the thermal management systems, which have evolved from rudimentary heat sinks to optimized natural convection heat sinks, forced air coolers, liquid coolers, and heat pipes. Although these cooling approaches are sufficient for keeping typical devices below about $130^{\circ} \mathrm{C}$ with heat fluxes less than $100 \mathrm{~W} / \mathrm{cm}^{2}$, the DARPA ICECool program sought to push the envelope of possible 
heat fluxes from semiconductor devices beyond $1 \mathrm{~kW} / \mathrm{cm}^{2}$ while keeping pumping power low [45]. This extreme cooling performance goal was realized via three fundamental heat transfer considerations: materials, topology, and fluids.

Desirable material properties for semiconductor thermal management include high thermal conductivity, heat capacity, and mechanical resistance to fatigue. Copper $(\mathrm{k}=400 \mathrm{~W} / \mathrm{m}-\mathrm{K}, \rho=9$ $\mathrm{g} / \mathrm{cm}^{3}$ ) is often the material of choice for thermal management of high heat flux electronics, since while aluminum is more than three times lighter, it is also about half as thermally conductive. For extremely high near-junction thermal transport, diamond $(\mathrm{k}=2000 \mathrm{~W} / \mathrm{m}-\mathrm{K})$ has shown increasing utility and manufacturability [46-48]. Altman et al. [46] showed that microchannels can be formed in diamond with an epitaxial $\mathrm{GaN}$ semiconductor on the active side of the $\mathrm{GaN}$ on diamond device.

Advantageous heat transfer topologies for semiconductor thermal management include high surface area to volume ratios, surface features that promote mixing for heat transfer enhancement, and short flow paths for minimal pressure drop. High surface area to volume features can be realized by fabricated microscale features, including microchannels, in the heat transfer surface via deep reactive ion etching $[49,50]$, microdeformation [51,52], and additive manufacturing [53,54]. Additive manufacturing has also repeatedly shown excellent utility in forming complex fluid manifolding paths for high heat flux electronics $[53,55]$. Other topologies that can realize extreme heat flux thermal management systems for semiconductors are those that eliminate thermal resistance, such as die attach, heat spreaders, and thermal interface materials. This "embedded cooling" approach brings the fluid as close as possible to the heat generation, increasing the manageable heat fluxes and cooling effectiveness [45].

Desirable fluid properties for highly effective thermal management include high thermal conductivity, high heat capacity, and high latent heat of vaporization (in two-phase cooling). Simultaneously, low viscosity is desirable for low pumping power. Through historical development of semiconductor coolers, the cooling fluid has evolved with increasing heat transfer coefficients in thermal management devices. Electronics coolers have progressed from passive air cooling to forced air cooling, then to forced liquid cooling and to passive two-phase cooling $[56,57]$. This trend is likely to continue, with a growing need for actively pumped two-phase cooling, as suggested by the growing number of studies on the topic. Pumped two-phase cooling is advantageous because it can remove more heat per pumping power than single-phase pumped cooling when configured correctly, and heat transfer coefficients generated by two-phase flows are considerably larger than those of single-phase flows under typical cooling conditions $[29,58]$. Further design possibilities for very high heat transfer coefficients include solid-liquid phase change materials, spray cooling, liquid metal cooling, and thermoelectric cooling $[50,59,60]$.

\subsection{High Heat Flux Two-Phase Coolers in Copper}

Each of the following high heat flux two-phase chip coolers are constructed of copper, making them approaches that could be applied to thermal management of power dense motors for aircraft propulsion. Each cooling approach shown in Table 1 utilizes area enhancement to maximize the heat transfer area exposed to diabatic two-phase flow. Each approach also uses manifolding in order to reduce the pressure drop while producing high heat transfer. The chip-scale coolers produced heat fluxes ranging from $200 \mathrm{~W} / \mathrm{cm}^{2}$ to $1230 \mathrm{~W} / \mathrm{cm}^{2}$ with temperature rises above the fluid reference temperature ranging from $22{ }^{\circ} \mathrm{C}$ to about $56{ }^{\circ} \mathrm{C}$, pressure drops ranging from $6 \mathrm{kPa}$ to $60 \mathrm{kPa}$, demonstrating the efficacy of localized pumped two-phase cooling. The differences in the studies include the approach by which surface area and other surface enhancements were achieved, as well as the type of manifolding and the cooling fluid. 
Table 1. High heat flux chip-scale two-phase cooling approaches in copper

\begin{tabular}{|c|c|c|c|c|c|c|c|c|c|}
\hline Ref. & Cooling Approach & Fluid & Sub-Cooling $\left({ }^{\circ} \mathrm{C}\right)$ & $\begin{array}{l}\text { Peak Heat Flux } \\
\left(\mathrm{W} / \mathrm{cm}^{2}\right)\end{array}$ & $\begin{array}{c}\text { Saturation } \\
\text { Temperature }\left({ }^{\circ} \mathrm{C}\right)\end{array}$ & Peak Super-Heat $\left({ }^{\circ} \mathrm{C}\right)$ & $\begin{array}{l}\text { Superheat Reference } \\
\text { Temperatures }\end{array}$ & Flow Rate & $\begin{array}{l}\text { Pressure } \\
\text { Drop (kPa) }\end{array}$ \\
\hline [61] & $\begin{array}{l}\text { Array of impinging jets on copper pin-fins coated } \\
\text { with microporous surface enhancement }\end{array}$ & HFE-7100 & 10 & 206 & $61^{1}$ & 35 & $T_{\text {heater }}-\mathrm{T}_{\text {sat }}$ & $30 \mathrm{~mL} / \mathrm{s}$ & 10.9 \\
\hline [62] & $\begin{array}{l}\text { Array of impinging jets on copper pin-fins coated } \\
\text { with microporous surface enhancement }\end{array}$ & R245fa & 5 & 218 & 45 & 22 & $\mathrm{~T}_{\text {heater }}-\mathrm{T}_{\text {in }}$ & $10 \mathrm{~g} / \mathrm{s}$ & 6.4 \\
\hline [63] & $\begin{array}{l}\text { Manifold microchannels in copper } \\
\text { Parallel microchannels in copper with }\end{array}$ & HFE-7100 & - & 300 & 60 & 50 & $\mathrm{~T}_{\text {surface }}-\mathrm{T}_{\text {sat }}$ & $4.2 \mathrm{~mL} / \mathrm{s}$ & - \\
\hline [64] & $\begin{array}{l}\text { non-contacting, tapered manifold expanding in } \\
\text { streamwise direction }\end{array}$ & Water & 10 & 506 & $100^{1}$ & 26.2 & $\mathrm{~T}_{\text {wall }}-\mathrm{T}_{\text {sat }}$ & $393 \mathrm{~kg} / \mathrm{m}^{2} \mathrm{~s}$ & - \\
\hline [52] & Manifold microchannels in copper & R245fa & 8.5 & 1230 & 36 & 56 & $T_{\text {wall }}-T_{\text {sat,av }}$ & $1400 \mathrm{~kg} / \mathrm{m}^{2} \mathrm{~s}$ & 60 \\
\hline
\end{tabular}

${ }^{1}$ At atmospheric pressure. 
The approaches used by Rau et al. [61] and Joshi and Dede [62] incorporated macroscale and microscale surface enhancements. The macroscale features were pin-fins, and a microporous coating was added, forming a multiscale surface enhancement. Both studies used similar manifolds, in which an array of 25 orifices produced jet impingement on the multiscale enhanced surface. Better performance was produced in the second study, which used R245fa in contrast to HFE-7100 [62]. In the second study, pressure drop and temperature rise were also reduced while peak heat flux was increased.

The approach reported by Kalani and Kandlikar [63] used a tapered manifold, which increased the cross-sectional flow area moving downstream with a non-contacting manifold above the microchannels. This approach may increase vapor venting and was reported to reduce the pressure drop while fundamentally altering the flow regimes occurring within the channels. A peak heat flux of $506 \mathrm{~W} / \mathrm{cm}^{2}$ was reported with a wall temperature of about $130^{\circ} \mathrm{C}$ with water as the working fluid.

Manifold-microchannels (MMC), the area enhancement geometry of interest in this dissertation for high heat flux two-phase cooling, were used by Baummer et al. [64] to achieve a base heat flux of $300 \mathrm{~W} / \mathrm{cm}^{2}$ with HFE-7100 as the working fluid. A later generation of the design achieved $1230 \mathrm{~W} / \mathrm{cm}^{2}$ with the low-pressure refrigerant R245fa as the working fluid [52]. So, it can be observed that MMC's can achieve very high heat fluxes with low superheats and low pressure drops in remote, chip-scale coolers.

\subsection{Comparison of Working Fluids}

As shown in Table 2, water is an excellent heat transfer fluid among several common fluids used for two-phase electronics cooling. The latent heat of vaporization and thermal conductivity of water are an order of magnitude greater than those of electronics cooling fluids (FC-72 and HFE-7100) and refrigerants often researched for electronics cooling (R236fa, R245fa, and R134a). Furthermore, the specific heat of water is more than three times greater than those fluids. Furthermore, high-purity water is orders of magnitude less expensive than any of the engineered fluids. Therefore, water is in many ways a natural choice for high heat flux cooling.

However, water is not without drawbacks for electronics cooling. Firstly, unless consistently deionized, water is an electrical conductor. Secondly, water is a solvent, and therefore should be carefully isolated from electronic devices. Furthermore, the atmospheric pressure saturation temperature of water is $100^{\circ} \mathrm{C}$, meaning that for two-phase operation, at atmospheric pressure, junction temperatures will be quite high. The saturation temperature can be reduced by operating the system under vacuum, but this approach raises reliability concerns of air ingress over time, a concern which is less relevant in systems operating with positive pressure. Water also has a higher freezing temperature than most engineering fluids, which could result in catastrophic failure in low ambient temperature environments; ethylene glycol reduces freezing temperature but is detrimental to thermal performance.

Engineered fluids can mitigate many of the concerns presented by water. These fluids are quite inert, dielectric, are available in a variety of saturation temperatures, and have a more favorable liquid-vapor density ratio. FC-72 has been considered the industry standard cooling fluid for singleand two-phase electronics cooling because of these favorable properties. HFE-7100, also manufactured by $3 \mathrm{M}$, has a lower global warming potential and $27 \%$ greater latent heat, but tends to be more corrosive than FC-72. R134a is an industry standard refrigerant and may soon be replaced by R1234ze in some applications.

The lower pressure refrigerants are reported more often for embedded semiconductor cooling, with R245fa being most common for its low pressure, high latent heat, and high thermal conductivity compared to R236fa. The room temperature saturation pressure of R245fa is about half that of R236fa, $1.5 \mathrm{~atm}$ compared to $2.7 \mathrm{~atm}$, respectively. This reduced pressure requirement reduces the structural strength required by the embedded cooling package, which may also be used to reduce package size and weight. Another advantage is that the latent heat of vaporization of R245fa exceeds that of R236fa by $31 \%$ (190 kJ/kg compared to $145 \mathrm{~kg} / \mathrm{kg}$ ) while the liquid thermal conductivity is also $17 \%$ 
higher $(0.081 \mathrm{~W} / \mathrm{m}-\mathrm{K}$ compared to $0.069 \mathrm{~W} / \mathrm{m}-\mathrm{K})$. These higher fluid property values both improve effectiveness of two-phase heat removal.

Automatic transmission fluid is not typically used in two-phase systems, in part due to its (intentionally) prohibitively high boiling temperature. It is, though, a potent single-phase cooling liquid, having specific heat about $30 \%$ greater, and thermal conductivity double that of common refrigerants. In addition to heat transfer, ATF is designed for hydrodynamic power transmission and lubrication [65].

The most common refrigerant used in vapor compression cycles is $\mathrm{R} 134 \mathrm{a}$, while $\mathrm{CO}_{2}$ is an increasingly commonly used fluid for transcritical and supercritical cycles. In contrast to vapor compression, transcritical cooling cycles pressurize the working fluid beyond the critical pressure and temperature of the fluid. This supercritical fluid is as dense as a liquid but expands and compresses much like a gas. For an R134a cycle rejecting heat at a fluid temperature of $70{ }^{\circ} \mathrm{C}$, the highest pressure occurring in the cycle is 21 bar. In contrast, a transcritical $\mathrm{CO}_{2}$ cycle rejecting heat at a fluid temperature of $70^{\circ} \mathrm{C}$ requires pressure to exceed 160 bar. This high pressure introduces some engineering challenges but provides significantly higher cooling system power density.

In particular, the size and weight of the heaviest and often bulkiest component of the refrigeration system, the compressor, can be significantly reduced. It has been shown that the compressor displacement can be reduced in excess of $80 \%$ when compared to a conventional R134a vapor compression cycle [66]. In pressure containment devices, including the compressor, thicker walls are required to contain the pressure, but the reduced internal volume decreases the total amount of material needed, resulting in decreased size and weight.

The benefits of transcritical $\mathrm{CO}_{2}$ as a refrigerant (also called R744) have been under investigation for two decades for automotive applications, and it has been shown that R744 can reduce the size, weight, and power required by the air conditioning system [67]. Mercedes-Benz committed to introducing transcritical $\mathrm{CO}_{2}$ cycles into their luxury automobiles for increased cooling performance, as well as the very low refrigerant global warming potential [68]. It should be noted that in order to realize the benefits, special precautions must be taken to mitigate the corrosive nature of supercritical $\mathrm{CO}_{2}$.

Table 2. Comparison of common working fluids for embedded two-phase coolers. All properties at 25 ${ }^{\circ} \mathrm{C}$ unless otherwise noted.

\begin{tabular}{|c|c|c|c|c|c|c|c|}
\hline Fluid & $\begin{array}{l}\text { Saturation Temperature at } \\
\text { Atmospheric Pressure }\left({ }^{\circ} \mathrm{C}\right)\end{array}$ & $\begin{array}{l}\text { Saturation } \\
\text { Pressure } \\
\text { (kPa) }\end{array}$ & $\begin{array}{c}\text { Specific } \\
\text { Heat } \\
(\mathrm{kJ} / \mathrm{kg}-\mathrm{K})\end{array}$ & $\begin{array}{c}\text { Latent Heat of } \\
\text { Vaporization }{ }^{1} \\
(\mathrm{~kJ} / \mathrm{kg})\end{array}$ & $\begin{array}{l}\text { Liquid Thermal } \\
\text { Conductivity } \\
\text { (W/m-K) }\end{array}$ & $\begin{array}{l}\text { Liquid } \\
\text { Density } \\
\left(\mathrm{kg} / \mathrm{m}^{3}\right)\end{array}$ & $\begin{array}{c}\text { Vapor } \\
\text { Density }{ }^{1} \\
\left(\mathrm{~kg} / \mathrm{m}^{3}\right)\end{array}$ \\
\hline FC-72 [69] & 56 & - & 1.1 & 88 & 0.057 & 1680 & 13 \\
\hline R236fa [70] & - & 272 & 1.24 & 145 & 0.069 & 1360 & 18 \\
\hline R245fa [70] & - & 148 & 1.32 & 190 & 0.081 & 1340 & 8.5 \\
\hline R134a [70] & - & 666 & 1.43 & 178 & 0.083 & 1210 & 32 \\
\hline ATF [65] & - & - & 1.95 & - & 0.16 & 870 & - \\
\hline
\end{tabular}

${ }^{1}$ At normal boiling point; ${ }^{2}$ Properties taken at $35^{\circ} \mathrm{C}$ and $10 \mathrm{MPa} ;{ }^{3}$ Supercritical fluid.

\section{Summary}

Novel, emerging electric propulsion systems for hybrid and electric aviation call for distributed electric propulsion to reduce drag and promote fuel efficiency and emission reductions. High efficiency and high specific power $(\mathrm{kW} / \mathrm{kg})$ electric motors are a key enabler for future electrification of aviation. This review focused on the role of thermal management and most recent improvements to the current thermal limitations of electric motors, with emphasis on approaches to increase the electrification of air transport. The study demonstrates that the commercial state-of-the art electric motors are thermally limited and that a substantial increase in power and torque density, as well as efficiency of electric motors can be achieved by mitigating the thermal limitations in electric motors through a co-design approach utilizing electromagnetics and thermomechanical design aspects. 
Current methods for commercial motor cooling—such as oil bath or water jacket cooling-impose limitations on power density due to lack of sufficient absorption of heat. This is particularly important for motors that benefit from operation at high voltages, which in turn require thick electrical insulation layers that often further limit heat dissipation. Researchers have shown that there exists significant potential for improved cooling. Specifically, the stator windings generate the majority of heat losses in electric motors, and examples show that from $43 \%$ to $64 \%$ of total motor heat generation occurs due to these resistive losses. By employing inter-winding and intra-winding thermal management, the power density of electric motors can be increased by a factor of three to five or more. Supercritical fluids that offer the density of a liquid and viscosity of a gas can also contribute to substantial additional cooling of motors with direct impact on enhancing power and torque densities and efficiency.

Recent studies have shown that the heat flux levels from semiconductor devices can be increased by more than ten-fold by placing thermal management as the top priority in the design and fabrication of high-performance devices. For electric motors the potential for such improvement can be even more significant realizing the same principles of thermally potent materials, topologies, and fluids. These approaches can be used to increase the power density of electric motors so that thermal management of electric motors will no longer lag that of semiconductors. An effective thermal management solution will optimally cool the motor itself as well as the integrated drive, the power electronics and the power conditioning system.

Author Contributions: Conceptualization, writing—review and editing, M.O.; investigation, writing—original draft preparation, D.C.D.

Funding: This research received no external funding.

Conflicts of Interest: The authors declare no conflicts of interest.

\section{References}

1. Airbus. Nearly 37,400 New Aircraft Valued at US\$5.8 Trillion Required over 20 Years. Available online: https:/www.airbus.com/newsroom/press-releases/en/2018/07/nearly-37-400-new-aircraftvalued-at-us-5-8-trillion-required-ov.html (accessed on 6 September 2019).

2. Airlines for America. A4A Passenger Airline Cost Index (PACI). Available online: http://airlines.org/dataset/ a4a-quarterly-passenger-airline-cost-index-u-s-passenger-airlines/ (accessed on 6 September 2019).

3. Gohardani, A.S.; Doulgeris, G.; Singh, R. Challenges of future aircraft propulsion: A review of distributed propulsion technology and its potential application for the all electric commercial aircraft. Prog. Aerosp. Sci. 2011, 47, 369-391. [CrossRef]

4. Madavan, N.; Heidmann, J.; Bowman, C.; Kascak, P.; Jankovsky, A.; Jansen, R. A NASA perspective on electric propulsion technologies for commercial aviation. In Proceedings of the Workshop on Technology Roadmap for Large Electric Machines, Urbana-Champaign, IL, USA, 5-6 April 2016; pp. 5-6.

5. Kasem, A.; Gamal, A.; Hany, A.; Gaballa, H.; Ahmed, K.; Romany, M.; Abdelkawy, M.; Abdelrahman, M.M. Design and implementation of an unmanned aerial vehicle with self-propulsive wing. Adv. Mech. Eng. 2019, 11, 1687814019857299. [CrossRef]

6. Moore, K.; Ning, A. Distributed Electric Propulsion Effects on Traditional Aircraft through Multidisciplinary Optimization. In Proceedings of the 2018 AIAA/ASCE/AHS/ASC Structures, Structural Dynamics, and Materials Conference, Kissimmee, FL, USA, 8-12 January 2018.

7. Bennion, K. Electric Motor Thermal Management RED 2016 NREL Annual Merit Review; National Renewable Energy Laboratory: Golden, CO, USA, 2016.

8. AVID Technology Limited. EVO Axial Flux Electric Motors. Available online: https://avidtp.com/product/ evo-motors/ (accessed on 6 September 2019).

9. YASA Limited. YASA 750R E-Motor. Available online: https://www.yasa.com/wp-content/uploads/2018/01/ YASA-750-Product-Sheet.pdf:2018 (accessed on 6 September 2019).

10. Moreels, D. Axial-Flux Motors and Generators Shrink Size, Weight. Available online: https:// www.powerelectronics.com/automotive/axial-flux-motors-and-generators-shrink-size-weight (accessed on 6 September 2019). 
11. Robinson, T. Bright Sparks—The Quest for Electric Speed. Available online: https://www.aerosociety.com/ news/bright-sparks-the-quest-for-electric-speed/ (accessed on 6 September 2019).

12. Dubois, A.; van der Geest, M.; Bevirt, J.; Clarke, S.; Christie, R.J.; Borer, N.K. Design of an Electric Propulsion System for SCEPTOR's Outboard Nacelle. In Proceedings of the 16th AIAA Aviation Technology, Integration, and Operations Conference, Washington, DC, USA, 13-17 June 2016.

13. Bolam, R.C.; Vagapov, Y.; Anuchin, A. Review of Electrically Powered Propulsion for Aircraft. In Proceedings of the 2018 53rd International Universities Power Engineering Conference (UPEC), Glasgow, UK, 4-7 September 2018; pp. 1-6.

14. Yang, Y.Y.; Bilgin, B.; Kasprzak, M.; Nalakath, S.; Sadek, H.; Preindl, M.; Cotton, J.; Schofield, N.; Emadi, A. Thermal management of electric machines. IET Electr. Syst. Transp. 2017, 7, 104-116. [CrossRef]

15. Ponomarev, P.; Polikarpova, M.; Pyrhonen, J. Thermal Modeling of Directly-Oil-Cooled Permanent Magnet Synchronous Machine. In Proceedings of the 2012 XXth International Conference on Electrical Machines (ICEM), Marseille, France, 2-5 September 2012; pp. 1882-1887.

16. Gonzalez, C. The Future of Electric Hybrid Aviation. Available online: https://www.machinedesign.com/ batteriespower-supplies/future-electric-hybrid-aviation (accessed on 6 September 2019).

17. Musto, M.; Bianco, N.; Rotondo, G.; Toscano, F.; Pezzella, G. A simplified methodology to simulate a heat exchanger in an aircraft's oil cooler by means of a Porous Media model. Appl. Therm. Eng. 2016, 94, 836-845. [CrossRef]

18. Sinnett, M. 787 No-Bleed Systems: Saving Fuel and Enhancing Operational Efficiencies. Available online: http://www.boeing.com/commercial/aeromagazine/articles/qtr_4_07/article_02_1.html (accessed on 6 September 2019).

19. Popescu, M.; Staton, D.; Boglietti, A.; Cavagnino, A.; Hawkins, D.; Goss, J. Modern Heat Extraction Systems for Electrical Machines-A Review. In Proceedings of the 2015 IEEE Workshop on Electrical Machines Design, Control and Diagnosis (Wemdcd), Torino, Italy, 26-27 March 2015; pp. 289-296.

20. Charoensawan, P.; Khandekar, S.; Groll, M.; Terdtoon, P. Closed loop pulsating heat pipes: Part A: Parametric experimental investigations. Appl. Therm. Eng. 2003, 23, 2009-2020. [CrossRef]

21. Adera, S.; Antao, D.; Raj, R.; Wang, E.N. Design of micropillar wicks for thin-film evaporation. Int. J. Heat Mass Transf. 2016, 101, 280-294. [CrossRef]

22. Corman, J.; Tompkins, R.; Edgar, R.; Mclaughlin, M. Rotating Electrical Machine Having Rotor and Stator Cooled by Means of Heat Pipes. U.S. Patent 3,801,843, 2 April 1974.

23. Hassett, T.; Hodowanec, M. Electric Motor with Heat Pipes. U.S. Patent 7,569,955, 4 August 2009.

24. McCluskey, F.P.; Saadon, Y.; Yao, Z.; Camacho, A. Cooling for Electric Aircraft Motors. In Proceedings of the 2019 18th IEEE Intersociety Conference on Thermal and Thermomechanical Phenomena in Electronic Systems (ITherm), Las Vegas, NV, USA, 28-31 May 2019; pp. 1134-1138.

25. Song, F.; Ewing, D.; Ching, C.Y. Heat transfer in the evaporator section of moderate-speed rotating heat pipes. Int. J. Heat Mass Transf. 2008, 51, 1542-1550. [CrossRef]

26. Faghri, A.; Gogineni, S.; Thomas, S. Vapor flow analysis of an axially rotating heat pipe. Int. J. Heat Mass Transf. 1993, 36, 2293-2303. [CrossRef]

27. Dehshali, M.E.; Nazari, M.; Shafii, M. Thermal performance of rotating closed-loop pulsating heat pipes: Experimental investigation and semi-empirical correlation. Int. J. Therm. Sci. 2018, 123, 14-26. [CrossRef]

28. Fedoseyev, L.; Pearce, E.M. Rotor Assembly with Heat Pipe Cooling System. U.S. Patent 9,331,552, 3 May 2016.

29. Agostini, B.; Thome, J.R.; Fabbri, M.; Michel, B. High heat flux two-phase cooling in silicon multimicrochannels. IEEE Trans. Compon. Packag. Technol. 2008, 31, 691-701. [CrossRef]

30. Garimella, S.V.; Sobhan, C.B. Transport in microchannels-A critical review. Annu. Rev. Heat Transf. 2003, 13, 1-50. [CrossRef]

31. Thome, J.R. Boiling in microchannels: A review of experiment and theory. Int. J. Heat Fluid Flow 2004, 25, 128-139. [CrossRef]

32. Pyrhonen, J.; Lindh, P.; Polikarpova, M.; Kurvinen, E.; Naumanen, V. Heat-transfer improvements in an axial-flux permanent-magnet synchronous machine. Appl. Therm. Eng. 2015, 76, 245-251. [CrossRef]

33. Rhebergen, C.; Bilgin, B.; Emadi, A.; Rowan, E.; Lo, J. Enhancement of Electric Motor Thermal Management through Axial Cooling Methods: A Materials Approach. In Proceedings of the 2015 IEEE Energy Conversion Congress and Exposition (ECCE), Montreal, QC, Canada, 20-24 September 2015; pp. 5682-5688. 
34. Sixel, W.; Liu, M.D.; Nellis, G.; Sarlioglu, B. Cooling of Windings in Electric Machines via 3D Printed Heat Exchanger. In Proceedings of the 2018 IEEE Energy Conversion Congress and Exposition (ECCE), Portland, OR, USA, 23-27 September 2018; pp. 229-235.

35. Semidey, S.A.; Mayor, J.R. Experimentation of an Electric Machine Technology Demonstrator Incorporating Direct Winding Heat Exchangers. IEEE Trans. Ind. Electron. 2014, 61, 5771-5778. [CrossRef]

36. Lindh, P.; Petrov, I.; Jaatinen-Värri, A.; Grönman, A.; Martinez-Iturralde, M.; Satrústegui, M.; Pyrhönen, J. Direct Liquid Cooling Method Verified With an Axial-Flux Permanent-Magnet Traction Machine Prototype. IEEE Trans. Ind. Electron. 2017, 64, 6086-6095. [CrossRef]

37. Wohlers, C.; Juris, P.; Kabelac, S.; Ponick, B. Design and direct liquid cooling of tooth-coil windings. Electr. Eng. 2018, 100, 2299-2308. [CrossRef]

38. Jahns, T.M.; Dai, H. The past, present, and future of power electronics integration technology in motor drives. CPSS Trans. Power Electron. Appl. 2017, 2, 197-216. [CrossRef]

39. Wang, J. Design of Multilevel Integrated Modular Motor Drive with Gallium Nitride Power Devices. Ph.D. Thesis, The University of Wisconsin-Madison, Madison, WI, USA, 2015.

40. Ditri, J.; Cadotte, R.; Fetterolf, D.; McNulty, M. Impact of microfluidic cooling on high power amplifier RF performance. In Proceedings of the 2016 15th IEEE Intersociety Conference on Thermal and Thermomechanical Phenomena in Electronic Systems (ITherm), Las Vegas, NV, USA, 31 May-3 June 2016; pp. 1501-1504.

41. Schultz, M.; Yang, F.H.; Colgan, E.; Polastre, R.; Dang, B.; Tsang, C.; Gaynes, M.; Parida, P.; Knickerbocker, J.; Chainer, T.; et al. Embedded Two-Phase Cooling Of Large 3d Compatible Chips With Radial Channels. In Proceedings of the International Technical Conference and Exhibition on Packaging and Integration of Electronic and Photonic Microsystems, San Francisco, CA, USA, 6-9 July 2015; Volume 3.

42. McCluskey, F.P.; Grzybowski, R.; Podlesak, T. High Temperature Electronics; CRC Press: Boca Raton, FL, USA, 1997.

43. Han, B.; Jang, C.; Bar-Cohen, A.; Song, B. Coupled Thermal and Thermo-Mechanical Design Assessment of High Power Light Emitting Diode. IEEE Trans. Compon. Packag. Technol. 2010, 33, 688-697. [CrossRef]

44. Bar-Cohen, A.; Robinson, F.L.; Deisenroth, D.C. Challenges and opportunities in Gen3 embedded cooling with high-quality microgap flow. In Proceedings of the 2018 International Conference on Electronics Packaging and iMAPS All Asia Conference (ICEP-IAAC), Mie, Japan, 17-21 April 2018; pp. K-1-K-12.

45. Bar-Cohen, A.; Maurer, J.J.; Felbinger, J.G. DARPA's intra/interchip enhanced cooling (ICECool) program. In Proceedings of the CS MANTECH Conference, New Orleans, LA, USA, 13-16 May 2013.

46. Altman, D.H.; Gupta, A.; Tyhach, M. Development of a Diamond Microfluidics-Based Intra-Chip Cooling Technology for GaN. In Proceedings of the ASME 2015 International Technical Conference and Exhibition on Packaging and Integration of Electronic and Photonic Microsystems collocated with the ASME 2015 13th International Conference on Nanochannels, Microchannels, and Minichannels, San Francisco, CA, USA, 6-9 July 2015.

47. Twitchen, D.J.; Pickles, C.S.J.; Coe, S.E.; Sussmann, R.S.; Hall, C.E. Thermal conductivity measurements on CVD diamond. Diam. Relat. Mater. 2001, 10, 731-735. [CrossRef]

48. Bar-Cohen, A.; Maurer, J.J.; Sivananthan, A.J.M.A. Near-junction microfluidic cooling for wide bandgap devices. MRS Adv. 2016, 1, 181-195. [CrossRef]

49. Deisenroth, D.C.; Mandel, R.K.; Greve, H.; Dessiatoun, S.V.; McCluskey, P.; Ohadi, M.M. Direct bonding of a titanium header to an embedded two-phase FEEDS cooling device for high-flux electronics. In Proceedings of the 2016 15th IEEE Intersociety Conference on Thermal and Thermomechanical Phenomena in Electronic Systems (ITherm), Las Vegas, NV, USA, 31 May-3 June 2016; pp. 1072-1077.

50. Bae, D.G.; Mandel, R.K.; Dessiatoun, S.V.; Rajgopal, S.; Roberts, S.P.; Mehregany, M.; Ohadi, M.M.; Orlando, F.L.U.S. Embedded two-phase cooling of high heat flux electronics on silicon carbide (SiC) using thin-film evaporation and an enhanced delivery system (FEEDS) manifold-microchannel cooler. In Proceedings of the 2017 16th IEEE Intersociety Conference on Thermal and Thermomechanical Phenomena in Electronic Systems (ITherm), Orlando, FL, USA, 30 May-2 June 2017; pp. 466-472.

51. Ohadi, M.; Choo, K.; Dessiatoun, S.; Cetegen, E. Next Generation Microchannel Heat Exchangers; Springer: New York, USA, 2013.

52. Cetegen, E. Force Fed Microchannel High Heat Flux Cooling Utilizing Microgrooved Surfaces. Ph.D. Thesis, University of Maryland, College Park, MD, USA, 2010. 
53. Dede, E.M.; Ishigaki, M.; Joshi, S.N.; Zhou, F. Design for additive manufacturing of wide band-gap power electronics components. In Proceedings of the 2016 International Symposium on 3D Power Electronics Integration and Manufacturing (3D-PEIM), Raleigh, NC, USA, 13-15 June 2016; pp. 1-20.

54. Arie, M.A.; Shooshtari, A.H.; Dessiatoun, S.V.; Al-Hajri, E.; Ohadi, M.M. Numerical modeling and thermal optimization of a single-phase flow manifold-microchannel plate heat exchanger. Int. J. Heat Mass Transf. 2015, 81, 478-489. [CrossRef]

55. Mandel, R.; Dessiatoun, S.; McCluskey, P.; Ohadi, M. Embedded Two-Phase Cooling of High Flux Electronics via Micro-Enabled Surfaces and Fluid Delivery Systems (FEEDS). In Proceedings of the ASME 2015 International Technical Conference and Exhibition on Packaging and Integration of Electronic and Photonic Microsystems collocated with the ASME 2015 13th International Conference on Nanochannels, Microchannels, and Minichannels, San Francisco, CA, USA, 6-9 July 2015.

56. Soule, C.A. Future trends in heat sink design. Electron. Cool. 2001, 7, 18-27.

57. Wilson, J. Cooling Solutions in the Past Decade. Electron. Cool. 2005, 11, 4.

58. Deisenroth, D.C. Two-Phase Flow Regimes and Heat Transfer in a Manifolded-Microgap. Ph.D. Thesis, University of Maryland, College Park, MD, USA, 2018.

59. McCluskey, P.; Saadon, Y.; Yao, Z.; Shah, J.; Kizito, J. Thermal Management Challenges in Turbo-Electric and Hybrid Electric Propulsion. In Proceedings of the 2018 International Energy Conversion Engineering Conference, Cincinnati, OH, USA, 9-11 July 2018; p. 4695.

60. Zhang, R.; Hodes, M.; Lower, N.; Wilcoxon, R. Water-Based Microchannel and Galinstan-Based Minichannel Cooling Beyond $1 \mathrm{~kW} / \mathrm{cm}^{2}$ Heat Flux. IEEE Trans. Compon. Packag. Manuf. Technol. 2015, 5, 762-770. [CrossRef]

61. Rau, M.J.; Garimella, S.V.; Dede, E.M.; Joshi, S.N. Boiling Heat Transfer from an Array of Round Jets with Hybrid Surface Enhancements. J. Heat Transf. Trans. Asme 2015, 137, 071501. [CrossRef]

62. Joshi, S.N.; Dede, E.M. Two-phase jet impingement cooling for high heat flux wide band-gap devices using multi-scale porous surfaces. Appl. Therm. Eng. 2017, 110, 10-17. [CrossRef]

63. Baummer, T.; Cetegen, E.; Ohadi, M.; Dessiatoun, S. Force-fed evaporation and condensation utilizing advanced micro-structured surfaces and micro-channels. Microelectron. J. 2008, 39, 975-980. [CrossRef]

64. Kalani, A.; Kandlikar, S.G. Flow patterns and heat transfer mechanisms during flow boiling over open microchannels in tapered manifold (OMM). Int. J. Heat Mass Transf. 2015, 89, 494-504. [CrossRef]

65. Quaiyum, M.A. Experimental investigation of Automatic Transmission Fluid (ATF) in an air cooled minichannel heat exchanger. Master's Thesis, University of Windsor, Ottawa, Canada, 2012.

66. Kim, M.H.; Pettersen, J.; Bullard, C.W. Fundamental process and system design issues in CO2 vapor compression systems. Prog. Energy Combust. Sci. 2004, 30, 119-174. [CrossRef]

67. California Air Resources Board. $\mathrm{CO}_{2}$ (R744) Systems Technology Update. In Proceedings of the Mobile Air Conditioning Summit, Sacramento, CA, USA, 15-16 March 2005.

68. Daimler. From 2017: First Vehicles with $\mathrm{CO}_{2}$ Air Conditioning. Available online: https://www.daimler.com/ sustainability/product/further-environmental-technologies/co2-air-conditioning-system.html (accessed on 4 January 2018).

69. Geisler, K. Dielectric Liquid Cooling of Immersed Components. In Encyclopedia of Thermal Packaging, 1st ed.; Bar-Cohen, A., Ed.; World Scientific Publishing Co. Pte. Ltd.: Hackensack, NJ, USA, 2013.

70. Klein, S.; Alvardo, F. EES-Engineering Equation Solver: User's Manual for Microsoft Windows Operating Systems; F-Chart Software: Madison, WI, USA, 2015.

71. Linstrom, P.J.; Mallard, W. NIST Chemistry Webbook; NIST standard reference database No. 69; NIST: Gaithersburg, MD, USA, 2018.

(C) 2019 by the authors. Licensee MDPI, Basel, Switzerland. This article is an open access article distributed under the terms and conditions of the Creative Commons Attribution (CC BY) license (http://creativecommons.org/licenses/by/4.0/). 